\title{
Article \\ Does Vancomycin Resistance Increase Mortality? Clinical Outcomes and Predictive Factors for Mortality in Patients with Enterococcus faecium Infections
}

\author{
Jatapat Hemapanpairoa ${ }^{1,2}$, Dhitiwat Changpradub ${ }^{3} \mathbb{D}$, Sudaluck Thunyaharn ${ }^{4}$ and \\ Wichai Santimaleeworagun $2,5, *$
}

check for

updates

Citation: Hemapanpairoa, J.; Changpradub, D.; Thunyaharn, S.; Santimaleeworagun, W. Does Vancomycin Resistance Increase Mortality? Clinical Outcomes and Predictive Factors for Mortality in Patients with Enterococcus faecium Infections. Antibiotics 2021, 10, 105 https://doi.org/10.3390/ antibiotics10020105

Academic Editor:

Jesus Simal-Gandara

Received: 27 December 2020

Accepted: 18 January 2021

Published: 22 January 2021

Publisher's Note: MDPI stays neutral with regard to jurisdictional claims in published maps and institutional affiliations.

Copyright: (c) 2021 by the authors. Licensee MDPI, Basel, Switzerland. This article is an open access article distributed under the terms and conditions of the Creative Commons Attribution (CC BY) license (https:/ / creativecommons.org/licenses/by/ $4.0 /)$.
1 Department of Pharmacy Practice and Pharmaceutical Care, Faculty of Pharmaceutical Sciences, Burapha University, Chonburi 20131, Thailand; aumloveka@gmail.com

2 Pharmaceutical Initiative for Resistant Bacteria and Infectious Disease Working Group [PIRBIG], Nakorn Pathom 73000, Thailand

3 Division of Infectious Disease, Department of Medicine, Phramongkutklao Hospital, Bangkok 10400, Thailand; dhitiwat@yahoo.com

4 Faculty of Medical Technology, Nakhonratchasima College, Nakhon Ratchasima 30000, Thailand; tanmicro@gmail.com

5 Department of Pharmacy, Faculty of Pharmacy, Silapakorn University, Nakorn Pathom 73000, Thailand

* Correspondence: santimaleeworag_w@silpakorn.edu; Tel.: +66-3425-580-0

\begin{abstract}
The prevalence of enterococcal infection, especially E. faecium, is increasing, and the issue of the impact of vancomycin resistance on clinical outcomes is controversial. This study aimed to investigate the clinical outcomes of infection caused by E. faecium and determine the risk factors associated with mortality. This retrospective study was performed at the Phramongkutklao Hospital during the period from 2014 to 2018. One hundred and forty-five patients with E. faecium infections were enrolled. The 30-day and 90-day mortality rates of patients infected with vancomycin resistant (VR)-E. faecium vs. vancomycin susceptible (VS)-E. faecium were $57.7 \%$ vs. $38.7 \%$ and $69.2 \%$ vs. $47.1 \%$, respectively. The median length of hospitalization was significantly longer in patients with VR-E. faecium infection. In logistic regression analysis, VR-E. faecium, Sequential Organ Failure Assessment (SOFA) scores, and bone and joint infections were significant risk factors associated with both 30-day and 90-day mortality. Moreover, Cox proportional hazards model showed that VR-E. faecium infection (HR 1.91; 95\%CI 1.09-3.37), SOFA scores of 6-9 points (HR 2.69; 95\%CI 1.15-6.29), SOFA scores $\geq 10$ points (HR 3.71; 95\%CI 1.70-8.13), and bone and joint infections (HR 0.08; $95 \% \mathrm{CI}$ 0.01-0.62) were significant risk factors for mortality. In conclusion, the present study confirmed the impact of VR-E. faecium infection on mortality and hospitalization duration. Thus, the appropriate antibiotic regimen for VR-E. faecium infection, especially for severely ill patients, is an effective strategy for improving treatment outcomes.
\end{abstract}

Keywords: Enterococci; survival; risk factor; VRE; glycopeptide

\section{Introduction}

Enterococcus, a gram-positive cocci occurring in chains, is a major pathogen in community and nosocomial infections. The infections caused by the Enterococci spp. includes the genitourinary tract, intra-abdomen, bloodstreams, infective endocarditis, skin/soft tissue, rarely bone and joint, and central nervous system. The species that are clinically important and the cause of most infections are E. faecalis and E. faecium [1]. However, E. faecalis is a common cause of community and in-hospital infection, while most E. faecium causes nosocomial infection. Additionally, E. faecium is generally resistant to penicillin (with ampicillin being a drug of choice for treatment of enterococcal infection) by the production of beta-lactamase and point mutation in penicillin-binding proteins (PBPs); it is 
occasionally reported resistant to vancomycin (also called vancomycin resistant Enterococci; VRE), by modifying pentapeptide precursors [1,2].

VRE isolates have been widely reported [3]. As per data from the National Healthcare Safety Network from 2009 to 2010, around 1/3 of all enterococcal associated nosocomial infections are VRE. It is noteworthy that VRE is the second most common cause of nosocomial infections in the United States of America [4,5]. As per the National Antimicrobial Resistance Surveillance, Thailand data, an increased prevalence of VRE was reported, from $0.4 \%$ in 2012 to $6.4 \%$ in 2019 , especially that of E. faecium that is resistant to vancomycin, which was $7.2 \%$ in 2019 [6].

Importantly, Enterococci can cause serious infection in debilitated patients. Patients can acquire enterococcal infections from colonization and the hospital environment. Patients infected with enterococci had a mortality rate of $32 \%-66.7 \%$ [7-14] depending on their prognostic factors, such as underlying diseases, Charlson Comorbidity Index (CCI), illness severity (Acute Physiology and Chronic Health Evaluation; APACHE) II, Pitt bacteremia, Organ System Failure Index; OSFI), admission to the intensive care unit (ICU), shock, active drug against VRE, and particularly infection caused by vancomycin-resistant strains [12,14-17].

However, several previous studies have shown that VRE infection is not associated with increased hospital deaths [18-21]. Whether the mortality among patients with VRE infection is higher than that among those with VSE remains a controversial issue. Additionally, certain studies described above gathered patient outcomes of E. faecium mixed with E. faecalis, and occasionally E. gallinarum [7-9,16,22]. Infection due to VR-E. faecium was associated with greater than 2 fold-higher risk of mortality as compared with infections caused by VR-E. faecalis [16].

Owing to the growing prevalence of enterococcal infection, especially E. faecium, the controversial impact of vancomycin resistance on clinical outcomes, and the available data pertaining non-specifically to infections due to E. faecium, this study aimed to investigate the clinical outcomes of infection due to E. faecium and determine the risk factors associated with mortality, including the risk attributed to vancomycin resistance.

\section{Results}

During the period from 2014 to 2018, there were 145 patients with E. faecium infection. Of these, 80 (55.2\%) were men, and the median patient age was 72 years (IQR 22 years). The median SOFA score was 5 points (IQR 7 points). Sixty (41.4\%) patients were admitted to the intensive care unit, and $71(49.0 \%)$ required mechanical ventilation. The most common comorbidity among patients with E. faecium infections was solid tumors (38.6\%), followed by cardiovascular diseases $(30.3 \%)$ and cerebrovascular diseases $(17.9 \%)$.

\subsection{Clinical Outcomes in Patients with VR-E. faecium and VS-E. faecium Infection}

The prevalence of VS-E. faecium and VR-E. faecium infection was $119(82.1 \%)$ and $26(17.9 \%)$, respectively. The baseline characteristics of the patients infected with VS-E. faecium and VR-E. faecium infection are shown in Table 1. Male sex, end stage kidney disease, bone/joint infection, and urinary tract infection were significantly different between patients infected with VS-E. faecium and VR-E. faecium infection. 
Table 1. Characteristics and clinical outcomes of patients infected with VR-E. faecium and VSE. faecium.

\begin{tabular}{|c|c|c|c|}
\hline \multirow{2}{*}{ Demographic Data } & \multicolumn{2}{|c|}{ Values } & \multirow{2}{*}{$p$-Value } \\
\hline & VR-E. faecium $(n=26)$ & VS-E. faecium $(n=119)$ & \\
\hline Male, $n(\%)$ & $19(73.1)$ & $61(51.3)$ & 0.043 \\
\hline Age, median (IQR), y & $68.5(57-80)$ & $74(59-80)$ & 0.62 \\
\hline \multicolumn{4}{|l|}{ Comorbidity, $n(\%)$} \\
\hline Cardiovascular diseases & $8(30.8)$ & $36(30.3)$ & 0.96 \\
\hline Cerebrovascular diseases & $3(11.5)$ & $23(19.3)$ & 0.57 \\
\hline End-stage kidney disease & $10(38.5)$ & $14(11.8)$ & 0.002 \\
\hline Liver disease & $6(23.1)$ & $13(10.9)$ & 0.11 \\
\hline Solid cancer & $7(26.9)$ & $49(41.2)$ & 0.18 \\
\hline Hematologic malignancy & $3(11.5)$ & $3(2.5)$ & 0.07 \\
\hline Neutropenia & $4(15.4)$ & $6(5)$ & 0.08 \\
\hline \multicolumn{4}{|l|}{ Ward, $n(\%)$} \\
\hline Medical-ICU & $11(42.3)$ & $32(26.9)$ & 0.12 \\
\hline Surgical-ICU & $3(11.5)$ & $14(11.8)$ & 1.0 \\
\hline Medicine & $7(26.9)$ & $43(36.1)$ & 0.37 \\
\hline Surgery & $5(19.2)$ & $29(24.4)$ & 0.58 \\
\hline Others & $0(0)$ & $1(0.8)$ & 1.0 \\
\hline SOFA score, median (IQR) & $7(7)$ & $5(7)$ & 0.11 \\
\hline Mechanical ventilator, $n(\%)$ & $16(61.5)$ & $55(46.2)$ & 0.16 \\
\hline E. faecium bacteremia, $n(\%)$ & $13(50)$ & $50(42)$ & 0.46 \\
\hline Polymicrobials, $n(\%)$ & $16(61.5)$ & $59(49.6)$ & 0.27 \\
\hline \multicolumn{4}{|l|}{ Type of infections, $n(\%)$} \\
\hline Bloodstream infection & $7(26.9)$ & $18(15.1)$ & 0.159 \\
\hline $\begin{array}{l}\text { Cardiovascular system } \\
\text { infection }\end{array}$ & 0 & $2(1.7)$ & 1.0 \\
\hline Intra-abdominal infection & $8(30.8)$ & $38(31.9)$ & 1.0 \\
\hline Bone and joint infection & $6(23.1)$ & $5(4.2)$ & 0.005 \\
\hline Skin and soft tissue infection & $2(7.7)$ & $15(12.6)$ & 0.539 \\
\hline Urinary tract infection & $3(11.5)$ & $39(32.8)$ & 0.033 \\
\hline Reproductive tract infection & $0(0)$ & $3(2.5)$ & 0.633 \\
\hline \multicolumn{4}{|l|}{ Clinical outcomes, $n(\%)$} \\
\hline In-hospital mortality & $19(73.1)$ & $59(49.6)$ & 0.03 \\
\hline 30-day mortality & $15(57.7)$ & $46(38.7)$ & 0.075 \\
\hline 90-day mortality & $18(69.2)$ & $56(47.1)$ & 0.04 \\
\hline $\begin{array}{l}\text { Length of hospitalization } \\
\text { (day), } \\
\text { median (IQR) }\end{array}$ & $69(38-124)$ & $36(24-58)$ & 0.001 \\
\hline
\end{tabular}

The 30-day and 90-day mortality rates in patients infected with VR-E. faecium vs. VS-E. faecium were $57.7 \%$ vs. $38.7 \%$ and $69.2 \%$ vs. $47.1 \%$, respectively (Table 1 ). The 30 -day and 90 -day mortality rates categorized by SOFA scores $(0-2,3-5,6-9$, and $\geq 10$ points) are shown in Figure 1. The in-hospital mortality rates for these patients were $73.1 \%$ and $49.6 \%$, respectively. The in-hospital mortality $(p=0.03)$ and 90 -day mortality rate $(p=0.04)$ was significantly different between patients with VS-E. faecium and VR-E. faecium infection. The median length of hospitalization was significantly longer in patients with VR-E. faecium infection than in those with VS-E. faecium (69 days vs. 36 days, $p=0.001$ ). 


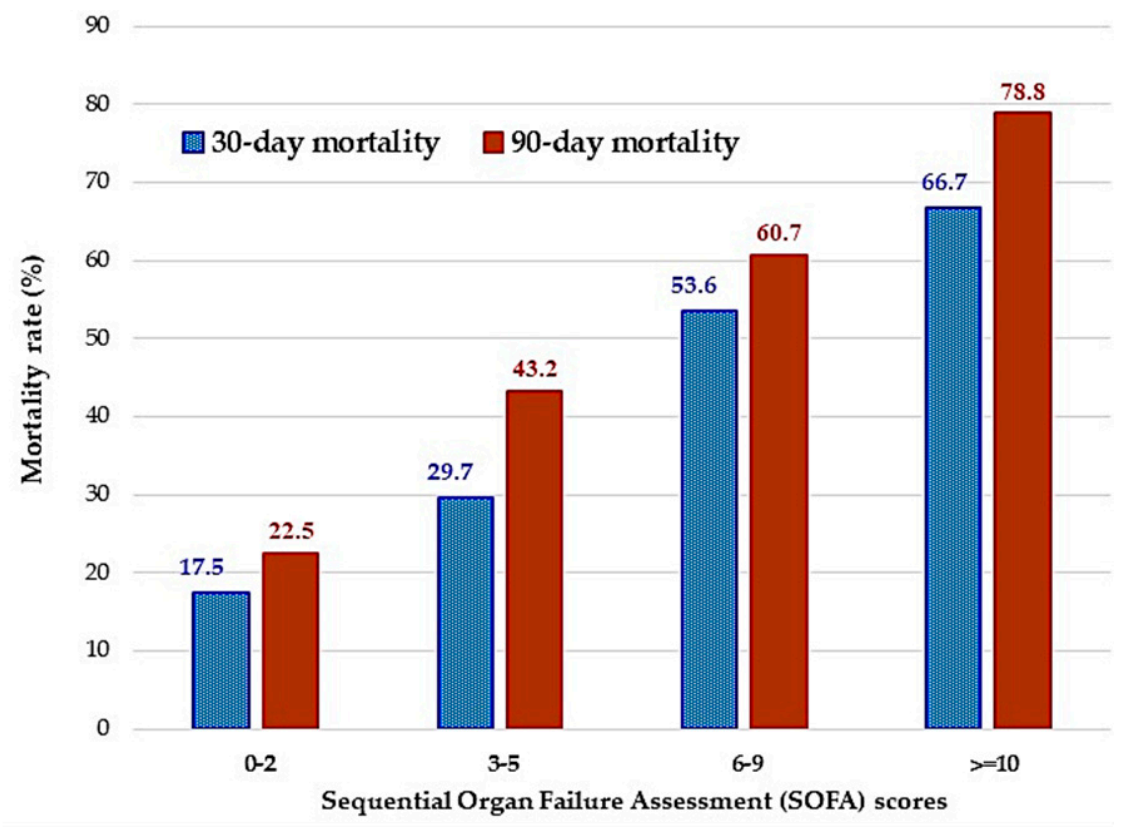

Figure 1. 30-day and 90-day mortality rates categorized by Sequential Organ Failure Assessment (SOFA) scores (0-2, 3-5, 6-9, and $\geq 10$ points).

\subsection{Risk Factors for 30-Day and 90-Day Mortality}

As per the univariate analysis for 30-day and 90-day mortality, those who died were aged $\geq 70$ years, had higher SOFA scores, had VRE infection, or had bacteremia. However, the prevalence of bone and joint infection was higher in the surviving patients. In logistic regression analysis, VR-E. faecium (aOR 3.64; 95\%CI 1.20-11.07), SOFA scores of 6-9 points (aOR 4.61; 95\%CI 1.43-14.87), and SOFA scores $\geq 10$ points (aOR 6.94; 95\%CI 2.23-21.59), and bone and joint infections (aOR 0.09; 95\%CI 0.01-0.91) were significant risk factors associated with 30-day mortality (Table 2 ). However, age $\geq 70$ years (aOR 3.56 ; 95\%CI 1.50-8.48), VR-E. faecium (aOR 7.35; 95\%CI 1.79-30.21), SOFA scores of 6-9 points (aOR $4.40 ; 95 \%$ CI 1.34-14.48), SOFA scores $\geq 10$ points (aOR 9.78; 95\%CI 2.93-32.70), and bone and joint infections (aOR $0.034 ; 95 \% \mathrm{CI} 0.02-0.49)$ were significant risk factors associated with 90-day mortality (Table 3).

Table 2. Factors predicting 30-day mortality among patients with Enterococcus faecium infections by univariate and multivariate analyses.

\begin{tabular}{|c|c|c|c|c|c|c|}
\hline \multirow{2}{*}{ Variables } & \multirow{2}{*}{$\begin{array}{c}\text { Death } \\
\text { (61 Cases) }\end{array}$} & \multirow{2}{*}{$\begin{array}{l}\text { Survivors } \\
\text { (84 Cases) }\end{array}$} & \multicolumn{2}{|c|}{ Univariate Analysis } & \multicolumn{2}{|c|}{ Multivariate Analysis † } \\
\hline & & & OR & $95 \%$ CI & aOR & $95 \% \mathrm{CI}$ \\
\hline Male, $n(\%)$ & $34(55.7)$ & $46(54.8)$ & 1.04 & $0.54-2.02$ & & \\
\hline Age $\geq 70$ years, $n(\%)$ & $41(50.6)$ & $40(49.4)$ & 2.26 & $1.14-4.47$ & 2.05 & $0.89-4.71$ \\
\hline \multicolumn{7}{|l|}{ Comorbidity, $n(\%)$} \\
\hline Cardiovascular diseases & $22(36.1)$ & $22(26.2)$ & 1.59 & $0.78-3.27$ & & \\
\hline Cerebrovascular diseases & $10(16.4)$ & $16(19)$ & 0.83 & $0.35-1.99$ & & \\
\hline End-stage kidney disease & $13(21.3)$ & $11(13.1)$ & 1.80 & $0.74-4.34$ & & \\
\hline Liver disease & $12(19.7)$ & $7(8.3)$ & 2.69 & $0.99-7.31$ & & \\
\hline Solid cancer & $21(34.4)$ & $35(41.7)$ & 0.74 & $0.37-1.46$ & & \\
\hline Hematologic malignancy & $3(4.9)$ & $3(3.6)$ & 1.40 & $0.27-7.17$ & & \\
\hline Neutropenia, $n(\%)$ & $6(9.8)$ & $4(4.8)$ & 2.18 & $0.59-8.09$ & & \\
\hline \multicolumn{7}{|l|}{ SOFA score, $n(\%)$} \\
\hline $0-2$ points & $7(12.7)$ & $33(39.8)$ & - & - & - & - \\
\hline $3-5$ points & $11(20)$ & $26(31.3)$ & 2.00 & $0.68-5.86$ & 1.52 & $0.49-4.71$ \\
\hline $6-9$ points & $15(27.3)$ & $13(15.7)$ & 5.44 & $1.81-16.39$ & 4.61 & $1.43-14.87$ \\
\hline$\geq 10$ points & $22(40)$ & $11(13.3)$ & 9.43 & $3.17-28.06$ & 6.94 & $2.23-21.59$ \\
\hline VR-E. faecium, n (\%) & $15(24.6)$ & $11(13.1)$ & 2.16 & $0.92-5.12$ & 3.64 & $1.20-11.07$ \\
\hline
\end{tabular}


Table 2. Cont.

\begin{tabular}{|c|c|c|c|c|c|c|}
\hline \multirow{2}{*}{ Variables } & \multirow{2}{*}{$\begin{array}{c}\text { Death } \\
\text { (61 Cases) }\end{array}$} & \multirow{2}{*}{$\begin{array}{l}\text { Survivors } \\
\text { (84 Cases) }\end{array}$} & \multicolumn{2}{|c|}{ Univariate Analysis } & \multicolumn{2}{|c|}{ Multivariate Analysis † } \\
\hline & & & OR & $95 \%$ CI & aOR & $95 \%$ CI \\
\hline \multicolumn{7}{|l|}{ Type of infections, $n(\%)$} \\
\hline Bloodstream infection & $16(26.2)$ & $9(10.7)$ & 2.96 & $1.21-7.26$ & \multirow{5}{*}{0.09} & \multirow{5}{*}{$0.01-0.91$} \\
\hline Intra-abdominal infection & $22(36.1)$ & $24(28.6)$ & 1.41 & $0.70-2.85$ & & \\
\hline Bone and joint infection & $1(1.6)$ & $10(11.9)$ & 0.12 & $0.02-0.99$ & & \\
\hline $\begin{array}{l}\text { Skin and soft tissue } \\
\text { infection }\end{array}$ & $4(6.6)$ & 13 (15.5) & 0.38 & $0.12-1.24$ & & \\
\hline Urinary tract infection & $17(27.9)$ & $25(29.8)$ & 0.91 & $0.44-1.89$ & & \\
\hline
\end{tabular}

Abbreviations: aOR, adjusted odds ratio; CI, confidence interval; $n$, number; OR, odds ratio; SOFA, sequential organ failure assessment. SOFA score increased as mortality increased; VR-E. faecium, vancomycin-resistant Enterococcus faecium. + By backward stepwise (conditional) method.

Table 3. Factors predicting 90-day mortality among patients with Enterococcus faecium infections by univariate and multivariate analyses.

\begin{tabular}{|c|c|c|c|c|c|c|}
\hline \multirow{2}{*}{ Variables } & \multirow{2}{*}{$\begin{array}{c}\text { Death } \\
\text { (74 Cases) }\end{array}$} & \multirow{2}{*}{$\begin{array}{l}\text { Survivors } \\
\text { (71 Cases) }\end{array}$} & \multicolumn{2}{|c|}{ Univariate Analysis } & \multicolumn{2}{|c|}{ Multivariate Analysis † } \\
\hline & & & OR & $95 \%$ CI & aOR & $95 \% \mathrm{CI}$ \\
\hline Male, n (\%) & $40(54.1)$ & $40(56.3)$ & 0.91 & $0.47-1.76$ & & \\
\hline Age $\geq 70$ years, $\mathrm{n}(\%)$ & $52(70.3)$ & $29(40.8)$ & 3.42 & $1.72-6.81$ & 3.56 & $1.50-8.48$ \\
\hline \multicolumn{7}{|l|}{ Comorbidity, n (\%) } \\
\hline Cardiovascular diseases & $26(35.1)$ & $18(25.4)$ & 1.6 & $0.78-3.27$ & & \\
\hline Cerebrovascular diseases & $14(18.9)$ & $12(16.9)$ & 1.15 & $0.49-2.69$ & & \\
\hline End-stage kidney disease & $16(21.6)$ & $8(11.3)$ & 2.2 & $0.87-5.45$ & & \\
\hline Liver disease & $13(17.6)$ & $6(8.5)$ & 2.31 & $0.83-6.46$ & & \\
\hline Solid cancer & $28(37.8)$ & $28(39.4)$ & 0.94 & $0.48-1.83$ & & \\
\hline Hematologic malignancy & $4(5.4)$ & $2(2.8)$ & 1.97 & $0.35-11.12$ & & \\
\hline Neutropenia, n (\%) & $7(9.5)$ & $3(4.2)$ & 2.37 & $0.59-9.55$ & & \\
\hline \multicolumn{7}{|l|}{ SOFA score, n (\%) } \\
\hline $0-2$ points & $9(13.2)$ & $31(44.3)$ & - & - & - & - \\
\hline $3-5$ points & $16(23.5)$ & $21(30)$ & 2.62 & $0.98-7.04$ & 1.89 & $0.64-5.59$ \\
\hline $6-9$ points & $17(25)$ & $11(15.7)$ & 5.32 & $1.84-15.38$ & 4.40 & $1.34-14.48$ \\
\hline$\geq 10$ points & $26(38.2)$ & $7(10)$ & 12.79 & $4.19-39.09$ & 9.78 & $2.93-32.70$ \\
\hline VR-E. faecium, n (\%) & $18(24.3)$ & $8(11.3)$ & 2.53 & $1.02-6.27$ & 7.35 & $1.79-30.21$ \\
\hline \multicolumn{7}{|l|}{ Type of infections, n (\%) } \\
\hline Bloodstream infection & $19(25.7)$ & $6(8.5)$ & 3.74 & $1.40-10.3$ & & \\
\hline Intra-abdominal infection & $25(33.8)$ & $21(29.6)$ & 1.22 & $0.60-2.45$ & & \\
\hline Bone and joint infection & $1(1.4)$ & $10(14.1)$ & 0.08 & $0.01-0.67$ & 0.034 & $0.02-0.49$ \\
\hline $\begin{array}{l}\text { Skin and soft tissue } \\
\text { infection }\end{array}$ & $6(8.1)$ & $11(15.5)$ & 0.48 & $0.17-1.38$ & & \\
\hline Urinary tract infection & $21(28.4)$ & $21(29.6)$ & 0.94 & $0.46-1.93$ & & \\
\hline
\end{tabular}

Abbreviations: aOR, adjusted odds ratio; $\mathrm{CI}$, confidence interval; $n$, number; OR, odds ratio; SOFA, sequential organ failure assessment. SOFA score increased as mortality increased; VR-E. faecium, vancomycin resistant Enterococcus faecium. + By backward stepwise (conditional) method. 


\subsection{Cox Proportional Hazard Regression Analysis of 90-Day Survival}

The factors related to 90-day survival that were significant on univariate analysis were further evaluated using a Cox proportional hazards model, and the hazard ratios were calculated. On multivariate analysis, VR-E. faecium (HR 1.91; 95\%CI 1.09-3.37), SOFA scores of 6-9 points (HR 2.69; 95\%CI 1.15-6.29), SOFA scores $\geq 10$ points (HR 3.71; 95\%CI 1.708.13 ), and bone and joint infections (HR $0.08 ; 95 \% \mathrm{CI} 0.01-0.62$ ) were significant risk factors for mortality (Table 4). The Cox proportional hazards cumulative 90-day survival curves with respect to different SOFA scores, vancomycin susceptibility pattern, and bone/joint infection vs. other organ infections are shown in Figure 2A-C, respectively.

Table 4. Multivariate Cox proportional hazard regression analysis of 90-day survival among patients with E. faecium infections $(n=145)$.

\begin{tabular}{cccc}
\hline Variable & Hazard Ratio & $\mathbf{9 5 \%} \mathbf{C I}$ & $p$-Value \\
\hline Age $\geq 70$ years & 1.61 & $0.92-2.82$ & 0.093 \\
VR-E. faecium infection & 1.91 & $1.09-3.37$ & 0.024 \\
SOFA score & & & \\
$0-2$ & Reference & Reference & - \\
$3-5$ & 1.06 & $0.47-2.52$ & 0.894 \\
$6-9$ & 2.69 & $1.15-6.29$ & 0.022 \\
$\geq 10$ & 3.71 & $1.70-8.13$ & 0.001 \\
Bloodstream infection & 1.02 & $0.57-1.83$ & 0.949 \\
Bone and joint infection & 0.08 & $0.01-0.62$ & 0.015 \\
\hline
\end{tabular}
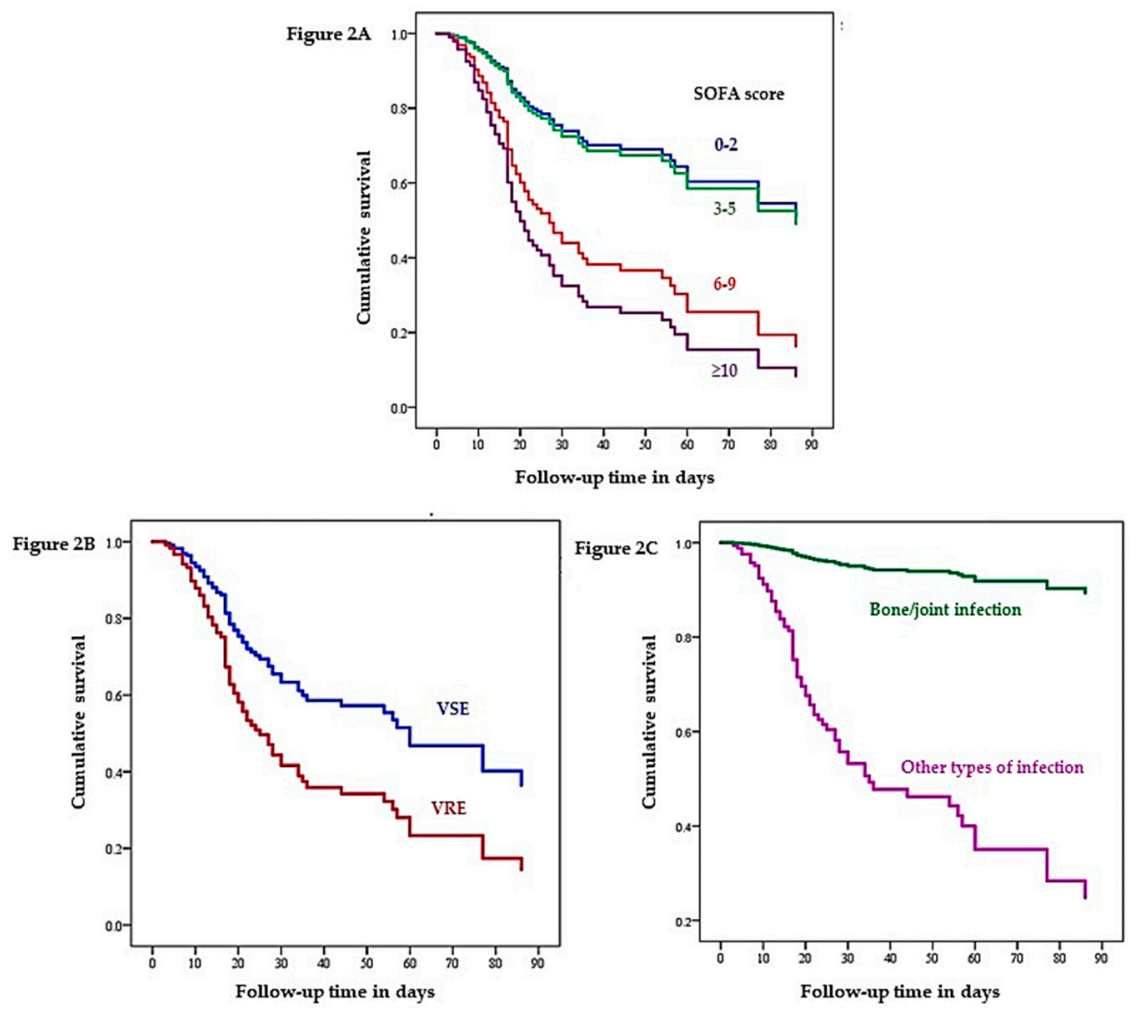

Figure 2. Cox proportional hazards cumulative 90-day survival curves with respect to different SOFA score groups (A), vancomycin susceptibility pattern (B), and bone/joint infection vs. other type of infections (C) after sepsis adjusted for other significant variables (age $\geq 70$ years, vancomycin resistance, bone/joint infection, or bloodstream infection). Abbreviations: SOFA, sequential organ failure assessment; VRE, vancomycin resistant Enterococci; VSE, vancomycin susceptible Enterococci. 


\section{Discussion}

Previously, several reports showed that patients with VRE versus those with VSE infection did not have a significantly greater risk of mortality [19-21]. In contrast, our study reported 30-day and 90-day mortality rates for VR-E. faecium infection patients of 57.7\% and $69.2 \%$, respectively; these values were obviously higher than those in patients with VS-E. faecium infection cases (38.7\% and $47.1 \%$ ). These results were similar to previous studies indicating the clinical impact of VRE on patient outcomes and hospitalization duration [14,23].

Moreover, the median length of hospitalization was significantly longer in patients with VR-E. faecium infection than in those with VS-E. faecium (69 days vs. 36 days). Prematunge et al. performed a meta-analysis of VRE and VSE bacteremia outcomes among hospital patients in the era of effective VRE therapy [24]. Among all the studies that were reviewed, the length of stay (LOS) was significantly longer in the VRE group than in the VSE group (mean difference, 5.01 days; 95\% CI, 0.58-9.44]) [24]. Similarly, we found an obvious increase in the duration of hospitalization among VR-E. faecium infection patients. Considering only the patients infected with VR-E. faecium, we also confirmed that VRE infection remained associated with an increased LOS. Therefore, the present study also conformed the influence of VR-E. faecium infection on patients. However, due to variable findings across previous studies, the role for vancomycin resistance in clinical significance has to be further evaluated.

As per multivariate and cox-regression analyses, the mortality rate was higher in patients with severe illness based on the SOFA scores and VR-E. faecium infection. A higher severity index score was a direct independent risk factor for mortality. Similar to previous reports $[8,18,20]$, we also found that the SOFA score increased the risk of poor outcome. Moreover, as for the type of infection, bone and joint infection was classified as decreasing the risk of death. Terpenning et al. [25] indicated that the most common sites for Enterococci isolation were the urinary tract, bone and soft tissue; however, the overall mortality rate in patients with bacteremia was as high as $71.4 \%$.

To our knowledge, no previous study has revealed the association between Enterococci bone and joint infection and death. Our result first documents this infection as a protective factor. However, certain evidence can explain this relationship. Thompson et al. [26] reviewed the treatment outcomes in 55 patients with enterococcal prosthetic joint infections during a 5 -year period. The overall cure rate was about $67 \%$; however, in cases where cure was intended, the overall rate was $80 \%$ [26]. Beyond the high cure rate for this type of infection, Fischbacher et al. [27] also documented that the 1-year cumulative mortality was $5.5 \%$, and the 2 -year rate was only $7.3 \%$. Thus, our findings confirmed bone and joint infection as a positive prognosis factor for E. faecium infection. However, the patients with bone and joint infection in this study had a significantly longer duration of hospitalization than the patients with other infections (median 42 days vs. 12 days, respectively). The enterococcal bone and joint infection thus seems not to impact on mortality but to increase medical costs.

As described above, the present findings indicated that VRE and severe illness were risk factors for mortality. However, it is difficult to select effective agents against Enterococci infection, especially in the VRE era, resulting in higher mortality [28]. As per a recent metaanalysis, linezolid treatment or higher-dose daptomycin $(\geq 9 \mathrm{mg} / \mathrm{kg}$ ) for VRE bacteremia were comparable in terms of the mortality rate. However, linezolid and higher-dose daptomycin were independently associated with lower mortality as compared with lower-dose daptomycin [29]. Therefore, the treatment of Enterococci with appropriate antimicrobial regimens could significantly reduce mortality [30].

Besides identifying effective agents against VRE infection, infection control in patients at risk of acquisition of VRE colonization is also important, especially immunocompromised patients, those with hematologic malignancy, organ transplantation, multiple comorbidities, prolonged hospitalization, staying in ICU, and close contact or staying on ward having patients with VRE colonization or infection [31,32]. Alevizakos et al. [33] performed a meta- 
analysis on the importance of colonization with VRE and found that colonized patients were 24 times more likely to develop a VRE bloodstream infection than non-colonized patients.

The current study has several limitations. First, it is a retrospective study with a small number of patients, which makes it difficult to determine all previous significant factors related mortality and length of stay [13]. Second, our findings were from a universityaffiliated hospital, which might be dissimilar from those taken at other types of hospitals. Further studies with a larger and multi-center sample are required to investigate the clinical outcomes of VRE infection.

\section{Materials and Methods}

\subsection{Study Design}

This retrospective study of risk factors related to mortality and clinical outcomes in patients infected with E. faecium was performed at the Phramongkutklao Hospital, a teaching hospital with 1200 inpatient beds for Phramongkutklao College of Medicine in Bangkok, Thailand, during the period from 2014 to 2018. The identification of Enterococci was performed using conventional techniques. The results of in vitro antimicrobial susceptibility tests for ampicillin and vancomycin with a disk-diffusion method were interpreted based on the Clinical and Laboratory Standards Institute [34]. The institutional review boards at Phramongkutklao College of Medicine and Phramongkutklao Hospital approved the study before its initiation (approval no. Q017b/61_Exp).

\subsection{Participants}

This study included participants (1) aged > 18 years; (2) with results for the first isolate of E. faecium; and (3) diagnosed with infection based on the Centers for Disease Control and Prevention/National Healthcare Safety Network (CDC/NHSN) Surveillance Definitions for Specific Types of Infections [35]. Patients who could not be followed up for treatment outcomes, those transferred to another hospital, and those with incomplete medical records were excluded.

\subsection{Data Collection}

The data of the enrolled study subjects were collected from medical records, and the subjects were concealed by coding. The following data were collected: (1) demographic data: gender, age, underlying diseases or comorbidity (malignant tumor, hematologic malignancy, chronic kidney disease, chronic liver function disease, diabetes, neutropenia [defined as neutrophil cell count being $<500 / \mathrm{mm}$ ], connective tissue disease, or cardiovascular disease), duration of admission, ward type when the patients had onset of infection, source of infections (based on CDC/NHSN), receiving anti-E. faecium therapy within $72 \mathrm{~h}$ from the onset of E. faecium infection, or septicemia. (2) Severity of illness: mechanical ventilator use, and Sequential Organ Failure Assessment (SOFA) score, mortality prediction score based on six organ dysfunction systems; SOFA score increased as mortality increased. (3) Mortality rate: in-hospital mortality, 30-day and 90-day mortality. In-hospital mortality was defined as death occurring during the hospital stay; 30- and 90-day mortality was defined as death occurring within 30 and 90 days of a diagnosis of infection.

\subsection{Statistical Analyses}

Descriptive statistics were used for depicting the participants' characteristics, clinical status, and mortality rate related to E. faecium infection. The 1-sample KolmogorovSmirnov test was performed for testing the normality of the continuous variables. Chisquare or Fisher's exact test were performed to analyze the relationship between the categorical variables. Mann Whitney $U$ test (median with interquartile range was used as appropriate) or independent $t$-test (mean with standard deviation was used as appropriate) were used to compare the median or mean, respectively, of continuous variables. All significant variables in the univariate analysis were considered for the logistic regression analysis based on the backward stepwise (conditional) method. All significant univariate 
factors were entered first, then considered for elimination based on the probability criteria for stepwise entry and removal.

For the survival analysis, a Cox's proportional hazard model for 90-day mortality among patients with E. faecium infection was employed. Cox's regression analysis was used for determining the independent risk factors for mortality by selecting the independent variables, that is, those with $p$-values $<0.1$ in the univariate analysis, to add into the final Cox's regression model. The results were reported as hazard ratios with $95 \%$ confidence intervals. Data were analyzed with SPSS (IBM Corp., Armonk, NY, USA), and a $p$-value $<0.05$ was considered statistically significant.

\section{Conclusions}

The present study indicated the impact of VR-E. faecium on mortality and duration of hospitalization. Additionally, severe illness was associated with poor treatment outcomes in patients with E. faecium infections. Therefore, in the resistant organism era, using individualized antibiotic regimens with optimal treatment support in severe patients, especially those with VR-E. faecium infection, might be a strategy to improve the treatment outcomes.

Author Contributions: Conceptualization, W.S. and D.C.; methodology, W.S. and D.C.; software, W.S.; validation, W.S. and J.H.; formal analysis, W.S. and J.H.; investigation, W.S. and J.H.; resources, W.S., J.H., D.C., and S.T.; data curation, W.S. and J.H.; writing—original draft preparation, W.S.; writing - review and editing, W.S., J.H., S.T. and D.C.; visualization, W.S. and J.H.; supervision, W.S.; project administration, W.S. All authors have read and agreed to the published version of the manuscript.

Funding: This research was funded by Faculty of Pharmacy, Silpakorn University.

Conflicts of Interest: The authors declare no conflict of interest.

\section{References}

1. Faron, M.L.; Ledeboer, N.A.; Buchan, B.W. Resistance Mechanisms, Epidemiology, and Approaches to Screening for VancomycinResistant Enterococcus in the Health Care Setting. J. Clin. Microbiol. 2016, 54, 2436-2447. [CrossRef]

2. Reyes, K.; Bardossy, A.C.; Zervos, M. Vancomycin-Resistant Enterococci: Epidemiology, Infection Prevention, and Control. Infect. Dis. Clin. North. Am. 2016, 30, 953-965. [CrossRef]

3. Gorrie, C.; Higgs, C.; Carter, G.; Stinear, T.P.; Howden, B. Genomics of vancomycin-resistant Enterococcus faecium. Microb. Genom. 2019, 5, e000283. [CrossRef]

4. Hidron, A.I.; Edwards, J.R.; Patel, J.; Horan, T.C.; Sievert, D.M.; Pollock, D.A.; Fridkin, S.K. National Healthcare Safety Network, T.; Participating National Healthcare Safety Network, F., NHSN annual update: Antimicrobial-resistant pathogens associated with healthcare-associated infections: Annual summary of data reported to the National Healthcare Safety Network at the Centers for Disease Control and Prevention, 2006-2007. Infect. Control. Hosp. Epidemiol. 2008, 29, 996-1011.

5. Sievert, D.M.; Ricks, P.; Edwards, J.R.; Schneider, A.; Patel, J.; Srinivasan, A.; Kallen, A.; Limbago, B.; Fridkin, S.; National Healthcare Safety Network (NHSN) Team; et al. Antimicrobial-resistant pathogens associated with healthcare-associated infections: Summary of data reported to the National Healthcare Safety Network at the Centers for Disease Control and Prevention, 2009-2010. Infect. Control Hosp. Epidemiol. 2013, 34, 1-14. [CrossRef]

6. The National Antimicrobial Resistant Surveillance Thailand. Antibiogram. Available online: http://narst.dmsc.moph.go.th/ (accessed on 10 April 2020).

7. Camins, B.C.; Farley, M.M.; Jernigan, J.J.; Ray, S.M.; Steinberg, J.P.; Blumberg, H.M. A population-based investigation of invasive vancomycin-resistant Enterococcus infection in metropolitan Atlanta, Georgia, and predictors of mortality. Infect. Control Hosp. Epidemiol. 2007, 28, 983-991. [CrossRef]

8. Han, S.H.; Chin, B.S.; Lee, H.S.; Jeong, S.J.; Choi, H.K.; Kim, C.O.; Yong, D.; Choi, J.Y.; Song, Y.G.; Lee, K.; et al. Vancomycinresistant enterococci bacteremia: Risk factors for mortality and influence of antimicrobial therapy on clinical outcome. J. Infect. 2009, 58, 182-190. [CrossRef]

9. Britt, N.S.; Potter, E.M.; Patel, N.; Steed, M.E. Comparison of the Effectiveness and Safety of Linezolid and Daptomycin in Vancomycin-Resistant Enterococcal Bloodstream Infection: A National Cohort Study of Veterans Affairs Patients. Clin. Infect. Dis. 2015, 61, 871-878. [CrossRef]

10. Ye, J.J; Shie, S.S.; Cheng, C.W.; Yang, J.H.; Huang, P.Y.; Wu, T.S.; Lee, M.H.; Huang, C.T. Clinical characteristics and treatment outcomes of vancomycin-resistant Enterococcus faecium bacteremia. J. Microbiol. Immunol. Infect. Wei Mian Yu Gan Ran Za Zhi 2018, 51, 705-716. [CrossRef]

11. Garbutt, J.M.; Ventrapragada, M.; Littenberg, B.; Mundy, L.M. Association between resistance to vancomycin and death in cases of Enterococcus faecium bacteremia. Clin. Infect. Dis. 2000, 30, 466-472. [CrossRef] 
12. Butler, A.M.; Olsen, M.A.; Merz, L.R.; Guth, R.M.; Woeltje, K.F.; Camins, B.C.; Fraser, V.J. Attributable costs of enterococcal bloodstream infections in a nonsurgical hospital cohort. Infect. Control Hosp. Epidemiol. 2010, 31, 28-35. [CrossRef] [PubMed]

13. Cheah, A.L.; Spelman, T.; Liew, D.; Peel, T.; Howden, B.P.; Spelman, D.; Grayson, M.L.; Nation, R.L.; Kong, D.C. Enterococcal bacteraemia: Factors influencing mortality, length of stay and costs of hospitalization. Clin. Microbiol. Infect. 2013, 19, E181-E189. [CrossRef] [PubMed]

14. Jiang, H.-L.; Zhou, Z.; Wang, L.-S.; Fang, Y.; Li, Y.-H.; Chu, C.-I. The Risk Factors, Costs, and Survival Analysis of Invasive VRE Infections at a Medical Center in Eastern Taiwan. Int. J. Infect. Dis. 2017, 54, 18-24. [CrossRef] [PubMed]

15. Gearhart, M.; Martin, J.; Rudich, S.; Thomas, M.; Wetzel, D.; Solomkin, J.; Hanaway, M.J.; Aranda-Michel, J.; Weber, F.; Trumball, L.; et al. Consequences of vancomycin-resistant Enterococcus in liver transplant recipients: A matched control study. Clin. Transplant. 2005, 19, 711-716. [CrossRef]

16. Hayakawa, K.; Marchaim, D.; Martin, E.T.; Tiwari, N.; Yousuf, A.; Sunkara, B.; Pulluru, H.; Kotra, H.; Hasan, A.; Bheemreddy, S.; et al. Comparison of the Clinical Characteristics and Outcomes Associated with Vancomycin-Resistant Enterococcus faecalis and Vancomycin-Resistant E. faecium Bacteremia. Antimicrob. Agents Chemother. 2012, 56, 2452. [CrossRef]

17. DiazGranados, C.A.; Zimmer, S.M.; Klein, M.; Jernigan, J.A. Comparison of mortality associated with vancomycin-resistant and vancomycin-susceptible enterococcal bloodstream infections: A meta-analysis. Clin. Infect. Dis. 2005, 41, 327-333. [CrossRef]

18. Lautenbach, E.; Bilker, W.B.; Brennan, P.J. Enterococcal bacteremia: Risk factors for vancomycin resistance and predictors of mortality. Infect. Control Hosp. Epidemiol. 1999, 20, 318-323. [CrossRef]

19. Shay, D.K.; Maloney, S.A.; Montecalvo, M.; Banerjee, S.; Wormser, G.P.; Arduino, M.J.; Bland, L.A.; Jarvis, W.R. Epidemiology and mortality risk of vancomycin-resistant enterococcal bloodstream infections. J. Infect. Dis. 1995, 172, 993-1000. [CrossRef]

20. Dubler, S.; Lenz, M.; Zimmermann, S.; Richter, D.C.; Weiss, K.H.; Mehrabi, A.; Mieth, M.; Bruckner, T.; Weigand, M.A.; Brenner, T.; et al. Does vancomycin resistance increase mortality in Enterococcus faecium bacteraemia after orthotopic liver transplantation? A retrospective study. Antimicrob. Resist. Infect. Control. 2020, 9, 22. [CrossRef]

21. Kramer, T.S.; Remschmidt, C.; Werner, S.; Behnke, M.; Schwab, F.; Werner, G.; Gastmeier, P.; Leistner, R. The importance of adjusting for enterococcus species when assessing the burden of vancomycin resistance: A cohort study including over 1000 cases of enterococcal bloodstream infections. Antimicrob. Resist. Infect. Control 2018, 7, 133. [CrossRef]

22. Chou, C.-H.; Lee, N.-Y.; Lee, H.-C.; Chang, C.-M.; Lee, C.-C.; Ko, W.-C. Emergence of vancomycin-resistant Enterococcus bloodstream infections in southern Taiwan. J. Microbiol. Immunol. Infect. 2012, 45, 221-227. [CrossRef]

23. Bhavnani, S.M.; Drake, J.A.; Forrest, A.; Deinhart, J.A.; Jones, R.N.; Biedenbach, D.J.; Ballow, C.H. A nationwide, multicenter, case-control study comparing risk factors, treatment, and outcome for vancomycin-resistant and -susceptible enterococcal bacteremia. Diagn. Microbiol. Infect. Dis. 2000, 36, 145-158. [CrossRef]

24. Prematunge, C.; MacDougall, C.; Johnstone, J.; Adomako, K.; Lam, F.; Robertson, J.; Garber, G. VRE and VSE Bacteremia Outcomes in the Era of Effective VRE Therapy: A Systematic Review and Meta-analysis. Infect. Control Hosp. Epidemiol. 2016, 37, 26-35. [CrossRef]

25. Terpenning, M.S.; Zervos, M.J.; Schaberg, D.R.; Kauffman, C.A. Enterococcal infections: An increasing problem in hospitalized patients. Infect. Control Hosp. Epidemiol. 1988, 9, 457-461. [CrossRef]

26. Thompson, O.; Rasmussen, M.; Stefansdottir, A.; Christensson, B.; Akesson, P. A population-based study on the treatment and outcome of enterococcal prosthetic joint infections. A consecutive series of 55 cases. J. Bone Jt. Infect. 2019, 4, 285-291. [CrossRef]

27. Fischbacher, A.; Borens, O. Prosthetic-joint Infections: Mortality Over the Last 10 Years. J. Bone Jt. Infect. 2019, 4, 198-202. [CrossRef]

28. Hemapanpairoa, J.; Changpradub, D.; Thunyaharn, S.; Santimaleeworagun, W. Vancomycin-resistant enterococcal infection in a Thai university hospital: Clinical characteristics, treatment outcomes, and synergistic effect. Infect. Drug Resist. 2019, 12, 2049-2057. [CrossRef]

29. Chuang, Y.C.; Lin, H.Y.; Chen, P.Y.; Lin, C.Y.; Wang, J.T.; Chang, S.C. Daptomycin versus linezolid for the treatment of vancomycinresistant enterococcal bacteraemia: Implications of daptomycin dose. Clin. Microbiol. Infect. 2016, 22, 890.e1-890.e7. [CrossRef]

30. Zasowski, E.J.; Claeys, K.C.; Lagnf, A.M.; Davis, S.L.; Rybak, M.J. Time Is of the Essence: The Impact of Delayed Antibiotic Therapy on Patient Outcomes in Hospital-Onset Enterococcal Bloodstream Infections. Clin. Infect. Dis. 2016, 62, 1242-1250. [CrossRef]

31. O'Driscoll, T.; Crank, C.W. Vancomycin-resistant enterococcal infections: Epidemiology, clinical manifestations, and optimal management. Infect. Drug Resist. 2015, 8, 217-230.

32. Rice, L.B. Emergence of vancomycin-resistant enterococci. Emerg. Infect. Dis. 2001, 7, 183-187. [CrossRef] [PubMed]

33. Alevizakos, M.; Gaitanidis, A.; Nasioudis, D.; Tori, K.; Flokas, M.E.; Mylonakis, E. Colonization With Vancomycin-Resistant Enterococci and Risk for Bloodstream Infection Among Patients with Malignancy: A Systematic Review and Meta-Analysis. Open Forum Infect. Dis. 2017, 4, ofw246. [CrossRef] [PubMed]

34. Clinical and Laboratory Standards Institute. Performance Standards for Antimicrobial Susceptibility Testing: Twenty-Ninth Informational Supplement; Clinical and Laboratory Standards Institute: Wayne, PA, USA, 2019; 149p.

35. CDC 2018 NHSN Patient Safety Component. Available online: https:/ / www.cdc.gov/nhsn/\# (accessed on 17 February 2019). 